\title{
Contribution of cytokines to pathology and protection in virus infection Andreas Wack ${ }^{1}$, Peter Openshaw ${ }^{2}$ and Anne O'Garra $^{1}$
}

\begin{abstract}
Acute and chronic viral infections greatly contribute to global health burden. While concerted action of multiple elements of the immune system help the host cope with most viruses, some infections lead to host damage or death. Cytokines are central drivers and controllers of both immune-mediated virus elimination and of immunopathology. Here, we review recent progress in understanding the protective and damaging roles in viral infections of cytokines and chemokines associated with innate, regulatory, and Th1, Th2 and Th17 responses.
\end{abstract}

Addresses: ${ }^{1}$ Division of Immunoregulation, The MRC National Institute for Medical Research, The Ridgeway, London NW7 1AA, UK. ${ }^{2}$ Centre for Respiratory Infection/MRC and Asthma UK Centre, Faculty of Medicine, Imperial College London, Norfolk Place, London W2 1PG, UK. 


\section{Introduction}

The immune system performs several difficult balancing acts when reacting to microbes. It is geared to eliminate pathogens and to tolerate non-pathogenic microbiota; it must mount a response to infection, but modulate the intensity and duration of the attack to limit damage to the host. There are numerous examples which show the adverse consequences of imbalanced cytokine networks during infection: immunopathology when pro-inflammatory cytokines are not controlled or regulatory cytokines are absent, and inefficient virus elimination leading to chronicity or pathogen-induced death when the cytokine response is qualitatively aberrant or too weak. A multitude of stromal and immune cell types deliver and receive cytokine signals, and viruses have evolved to suppress or subvert cytokine induction or evade the consequences of cytokine action. While we are beginning to understand parts of these networks, there are certainly still more questions than answers, and the modulation of cytokine actions for therapeutic use in infection is still in its infancy. Here, we describe recent progress in the understanding of cytokines and chemokines contributing to damage and protection during viral infection and viral - bacterial coinfections. We structure this review roughly following the families of cytokines involved in different response types (cytokines involved in innate immune responses, "regulatory" cytokines, Th17-, Th1-, Th2-associated cytokines). The importance of cytokines in antiviral protection is demonstrated by the fact that most (if not all) viruses show signs that they have evolved to block the action of key immune mediators. For example, Poxvirus genomes typically encode approximately 200 genes, about 90 of which are in the central genome and encode essential viral proteins. The genes that cluster at each end of the genome tend to be host species-specific and show evidence of horizontal eukaryotic gene transfer, conferring an advantage to the virus in controlling host responses to infection $[1,2]$. 


\section{Cytokines involved in the innate immune response}

\section{Type I and III interferons and viruses}

Type I interferons (IFNs) are a family of secreted cytokines comprised of more than 10 distinct IFNalpha $(\alpha)$ genes, one IFNbeta $(\beta)$ gene and several other family members, which all elicit distinct antiviral effects. IFNs were first described by Isaacs and Lindenmann as soluble factors released from influenza virus infected cells that expressed anti-viral properties [3]. These properties are mediated through a vast number of effector molecules that are induced by autocrine or paracrine binding of IFN $\beta /$ IFN $\alpha$ to the IFN $\alpha \beta$ receptor (reviewed in $[4,5])$. In 2003, three highly related cytokines were discovered independently by two research groups: IL-28A, IL-28B and IL-29 [6,7]. They are also designated as IFN- $\lambda 2, \lambda 3$, and $\lambda 1$, respectively, or together as type III IFNs. These mediators (reviewed in [8]) are part of a larger family of related cytokines called the IL-10IFN family, which additionally contains the IL-10-like cytokines (IL-10, IL-19, IL20, IL-22, IL-24, and IL-26), the type I IFNs (in humans: thirteen IFN $\alpha$ species, IFN $\beta$, IFNE, IFNא, and IFNש), and the type II IFN, IFN $\gamma$. Type I and Type III IFNs signal through Stat1/Stat2, albeit downstream of distinct receptors (Reviewed in $[8,9])$.

The range of effector mechanisms downstream of IFN signaling is wide and continues to grow (reviewed in [10]). Type I IFNs themselves also induce a positive feedback loop and trigger the expression of IFN-inducing proteins such as RIG-I, NF- $\mathrm{BB}$ and STATs. Probably the best indication of the potent anti-viral effects of type I IFNs is the fact that many viruses dedicate part of their limited genome to counteracting type I IFN induction and signaling [5]. That IFN $\alpha$ in combination with antivirals is successfully used as a therapy for chronic hepatitis $\mathrm{C}$ virus (HCV) infection underlines the practical implications of the protective potential of IFNs [11]. 
As both IFN $\alpha$ and $\beta$ exclusively signal through the IFN $\alpha \beta R$, the requirement of type I IFNs in viral infection has been extensively tested in IFN $\alpha \beta R$ deficient mice. The original papers showed increased susceptibility to infection by vesicular stomatitis virus (VSV), Semliki Forest virus, vaccinia virus and lymphocytic choriomeningitis virus (LCMV) [12]. Additional viruses such as Theiler's virus and murine cytomegalovirus (MCMV) were added to the list of viruses targeted by IFN $\alpha \beta$ (reviewed in [13]). More recently, infection by chikungunya virus was shown to be controlled by IFN $\alpha \beta$ in mice [14]. Interestingly, the virus appears not to induce IFN $\alpha \beta$ in immune cells, and protection in mice depends on IFN $\alpha \beta$ signaling in host stromal cells, as determined in bone marrow chimeras. Similarly, in a study comparing IFN $\alpha \beta$ induction by respiratory syncytial virus (RSV) and influenza virus, the respiratory epithelium was a major source of IFN $\alpha \beta$ in either infection, but depletion of plasmacytoid dendritic cells (pDC) had a major effect on type I IFN production only in the case of influenza infection [15].

To further illustrate the complexity of the picture with influenza virus infection, IFN $\alpha \beta R$ KO mice show systemic viral dissemination with little to no increase in host susceptibility after infection with low pathogenicity influenza virus strains [16-18], while a slightly greater effect is found when H5N1 viruses were used [19]. Similarly, IFN $\beta$-deficient mice show a higher susceptibility to influenza infection [20]. The reason for the relatively mild phenotype most likely lies in the redundancy of the IFN systems. More dramatic increases in susceptibility are observed in mice lacking also another IFN system, namely IFN- $\lambda$ (IL-28) [21]. Thus, STAT1 KO mice in which signaling through either IFN $\alpha \beta$, IFN $\gamma$ (IFN-Type II) or IFN-lambda (IFN-Type III - including IL-28 and IL-29) is altered show higher susceptibility [16,17], as do the IFN $\alpha \beta R / I L 28 R$ double deficient mice [21]. This is especially so if they also express a functional Mx gene [22] which in mice appears to play a predominant protective role among the many genes induced by IFN. Another factor possibly explaining the apparent relatively minor contribution of IFN $\alpha \beta$ may be the highly efficient shut-off of IFN induction and signaling by influenza virus, underscored by findings showing that viruses 
deficient in the IFN-suppressing protein NS1 show greater differences in virulence in IFN-deficient as opposed to IFN-sufficient systems [23].

IFN $\alpha \beta$ have not only antiviral but also immunomodulatory functions for the production of pro-inflammatory cytokines. This may explain some of the results in human infection with the highly pathogenic 1918 'Spanish Flu' strain and the H5N1 avian strains, where hypercytokinemia- associated immunopathology [24] was proposed as one the factors contributing to high mortality (reviewed in [2527]). Studies of macaques infected with H5N1 strains showed early and strong induction of IFN $\alpha \beta$ and proinflammatory cytokines [28]. This is in line with the notion that type I IFNs can induce secretion of cytokines such as TNF $\alpha$, IL-6 and IFN $\gamma$ and with in vitro data demonstrating that human macrophages secrete high levels of IFN $\beta$ within hours of H5N1 infection in vitro $[29,30]$, and would suggest that the pro-inflammatory effects of IFN $\alpha \beta$ may dominate over its antiviral action under some circumstances. In contrast, studies conducted on human bronchial epithelial cells suggest that type I IFN levels are lower in response to infection with highly pathogenic H5N1 as compared to seasonal strains [31]. Similarly, severe disease due to the highly pathogenic 1918 strain of H1N1 in macaques is correlated with persisting low levels of type I IFNs [32]. In this study, lower levels of IFN $\alpha \beta$ induced by the 1918 strain are associated with higher levels of IL-6 and other pro-inflammatory cytokines. A more recent study correlates susceptibility or resistance to the same H5N1 virus in back crosses of different mouse strains and describes that susceptibility correlates directly with levels of pro-inflammatory cytokines and inversely with IFN $\alpha \beta$ levels [33]. Therefore, reduced IFN $\alpha \beta$ levels may explain reduced virus control, consistent with the established antiviral role of IFN $\alpha \beta$.

An additional or alternative explanation has been suggested for how reduced IFN $\alpha \beta$ levels may lead to reduced virus control. Recent results demonstrate that IFN $\alpha \beta$ antagonizes inflammasome and IL-1 induction [34]. Therefore, if highly pathogenic influenza strains are more efficient in suppressing IFN $\alpha \beta$, then this may also allow higher levels of inflammasome activity, higher production of 
mature IL-1 and strong induction of pro-inflammatory cytokines, which could lead to enhanced pathology. However, the inverse correlation between IFN $\alpha \beta$ and a range of pro-inflammatory cytokines has not always been reported to be the case. In addition to the examples cited above, a recent study of the cytokine response of human epithelial cells to highly pathogenic H7N7 viruses showed that the induction of both IFN $\alpha \beta$ and pro-inflammatory cytokines was attenuated in response to H7N7 [35]. However, it is possible that different effects on different cells of the innate and adaptive immune response may result in differential production of Type I IFNs and proinflammatory cytokines, which together will contribute to either viral clearance and/or immunopathology.

\section{IFN $\alpha \beta$ and co-infection}

The immunmodulatory functions of IFN $\alpha \beta$ will impact not only on the course of the primary viral infection, but also on subsequent infection.

\section{Type I IFNs can promote bacterial infections}

It has become clear in recent years that the majority of patients dying with influenza develop severe bacterial pneumonia, and the reasons for the increased susceptibility to co-infection are under intense study [36]. The production of type I IFN is associated with suppression of the innate response to bacterial infections. Indeed, indications that IFN $\alpha \beta$ may interfere with antibacterial responses came from Listeria models where IFN $\alpha \beta$ deficient mice were shown to be more resistant to infection [37-39]. The same observation was made recently in infection with the parasite Trypanosoma cruzi [40]. Similarly, infection with Mycobacterium tuberculosis is more severe when mice are pre-treated with poly I:C, and this effect has been shown to be IFN $\alpha \beta$-mediated [41]. Several mechanisms have been put forward to explain this phenomenon, one of which is the inhibition of inflammasome activation and IL-1 production, as mentioned above [34]. In this study, poly I:C-induced IFN $\alpha \beta$ was shown to reduce IL-1 $\beta$ production which renders subsequent Candida infection more efficient [34]. 
Other explanations include the interference of IFN $\alpha \beta$ with IFN $\gamma$ signalling in Listeria infection [42], the suppression of Th17 induction by IFN $\alpha \beta$-dependent inhibition of osteopontin, which leads to de-repression of the regulatory cytokine IL27 in DCs and reduced and delayed Th17 responses [43], or reduction of the neutrophil chemoattractants KC and MIP-2, leading to decreased neutrophil influx for antibacterial action [44]. Seo et al [45] propose a cellular explanation for the differential induction of neutrophil chemoattractants in IFN $\alpha \beta R$-deficient mice upon influenza infection. In these mice, a different monocyte subset expressing intermediate levels of Ly6C was seen to be promoted in contrast to observations in wild type animals. These Ly6C intermediate monocytes produced more $\mathrm{KC}$ and Mip-2 leading to neutrophil influx in contrast to the Ly6C high monocytes induced in wild type mice which were strong producers of the monocyte chemoattractant MCP-1 (CCL2). In MCMV infection, IFN $\alpha \beta$ was shown to be responsible for CCL-2, -7 and -12 induction in the bone marrow, which serve as release factors for Ly6Chi inflammatory monocytes [46], which may explain the reduction of this monocyte subset in IFN $\alpha \beta$ R-deficient mice.

\section{Viral suppression of IFN $\alpha \beta$ can promote infection with opportunistic viruses.}

In contrast to the described effects of IFN $\alpha \beta$ promoting bacterial superinfection, certain viruses can suppress the production of Type I IFNs and render mice susceptible to superinfection with opportunistic viruses. For example, LCMV has been shown to facilitate viral superinfection by impairing IFN $\alpha \beta$ production by pDCs and consequently decreasing NK cell activation leading to reduced control and increased early spread of MCMV used as a model for an opportunistic pathogen [47]. This report is in line with previous in vitro findings of efficient suppression of IFN $\alpha \beta$ production in human pDCs by measles virus and some strains of RSV, viruses associated with opportunistic infections and pathology $[48,49]$. In conclusion, the immunomodulatory roles of IFN $\alpha \beta s$ appear to be as 
complex as their antiviral roles, and the impact of IFN $\alpha \beta$ in viral, bacterial and in co-infections will keep researchers busy for years to come.

\section{TNF, IL-6, IL-1 and inflammasomes in virus infection}

As mentioned above, infection with highly pathogenic influenza strains is linked to hypercytokinemia [24], even though the causal relationship between pathogenicity and cytokines is still unclear. Studies in mice have confirmed the strong cytokine induction by highly pathogenic strains [27], but contributions of individual cytokines to disease severity have been difficult to pin down in cytokine-deficient mice. When mice deficient for IL-6, one of the most highly upregulated cytokines in infection with pathogenic influenza, were analyzed, no changes in susceptibility were found [50]. These results confirm older data obtained with low pathogenicity-strains [51]. In contrast, TNFR1 KO mice showed a slight delay in weight loss in response to high pathogenicity influenza infection [50], suggesting a minor contribution of TNF $\alpha$ to pathology, whereas in other studies of influenza and RSV infection, inhibition of TNF reduced the severity of virus-specific lung immunopathology, inhibited T cell recruitment and attenuated viral clearance [52,53].

Early publications show higher mortality of mice deficient in IL-1R1 or IL-1 $\beta$ in response to influenza infection [54,55]. This was confirmed by more recent results obtained with high pathogenicity influenza virus strains [50]. These results suggest that although IL-1 may contribute to lung pathology it simultaneously contributes to virus clearance and resistance [27]. Three studies have attempted to assess the requirements of inflammasome components for the immune response to influenza (reviewed in [56]). As inflammasomes are thought to be sensors of the integrity of cellular membranes, it may not come as a surprise that expression of the influenza proton channel M2 by infected cells strongly induces inflammasomes [57]. One of the three mentioned studies uses the potent inflammasome inducer alum to apply the virus intranasally [58]. The other two studies both show that mice deficient in inflammasome components have increased mortality relatively late in influenza infection, and reach slightly 
divergent conclusions $[59,60]$. Thomas et al associated higher susceptibility to influenza of Nlrp3- (=Nalp3-) and caspase1-deficient mice with lower neutrophil and macrophage influx [59]. Ichinoe and colleagues, in contrast, reported higher susceptibility in mice deficient in apoptosis-associated speck-like protein containing a caspase recruitment domain (ASC) and in caspase 1-deficient mice, but not in Nalp3 deficient mice, and concentrated their study on effects on the induction of the adaptive response [60]. Major methodological differences between the latter two studies include different Nalp-3 deficient mouse strains used, and use of a lower infectious viral dose in the study of Ichinoe et al. Together, these data suggest a contribution of the inflammasome and of IL-1 $\beta$ in protection against influenza, and further studies are awaited to understand which mechanisms are at work. However, IL-1 induction does not always equate with inflammasome action. An interesting study of adenovirus-associated inflammation shows that this is mediated by IL-1 $\alpha$ rather than IL-1 $\beta$, and that IL$1 \alpha$ processing for maturation is inflammasome-independent but dependent on beta 3 integrin [61]. It is important to understand the details of adenovirusinduced inflammation as this represents one of the main complications of prophylactic or therapeutic approaches using adenovirus vectors.

\section{Chemokines and anti-viral responses}

\section{CCR2- and CCR5 dependent chemokines}

Viruses have evolved numerous strategies to evade innate and acquired immune responses that may eliminate them in the infected host. Large DNA viruses, such as herpesviruses and poxviruses, encode homologues of chemokine ligands and chemokine receptors, and secreted chemokine binding proteins (CKBPs) to modulate chemokine activity (reviewed in [62]) demonstrating the importance of chemokines in protection against viral infection.

Most chemokines bind to more than one receptor, and most chemokine receptors recognize more than one ligand, making analysis of this complex network by the use of single-gene targeted mice difficult. In the case of the monocyte and T cell chemokines Mip-1 $\alpha$ (CCL3), Mip-1 $\beta$ (CCL4) and RANTES 
(CCL5) which all bind to CCR5, some clarity has been achieved. The original report on Mip-1 $\alpha$ deficient mice showed that Coxsackievirus-induced myocarditis and influenza-induced pulmonitis were reduced [63], while little or no contribution of Mip-1 $\alpha$ to susceptibility to high pathogenicity influenza was found in later studies [50]. CCR5 KO mice were more susceptible to influenza infection showing higher mortality, increased monocyte recruitment to the lung and enhanced pulmonary pathology [64]. Subsequent studies confirmed the increased susceptibility with another influenza virus strain and with Sendai virus [65]. The finding that RANTES deficient mice closely resembled the CCR5 phenotype [65] suggests that RANTES, not Mip-1 $\alpha$ is the predominant CCR5 ligand in action in respiratory viral infection. The main effect observed in CCR5 and RANTES deficient mice was not a lack in cell recruitment, but increased macrophage apoptosis, suggesting that CCR5 promotes macrophage survival which, in turn helps clear the virus. RSV infection of epithelial cells and macrophages results in production of RANTES by resident cells during the first $48 \mathrm{~h}$ of infection leading to recruitment of CD4+ and CD8+ T cells and plays an important role in controlling viral replication [66]. Later, RANTES from resident cells disappears, to be replaced by virally induced RANTES from recruited T cells. Blocking RANTES with Met-RANTES at this time reduces immunopathology but does not influence the Th1/Th2 balance. This study suggested that RANTES plays a central role in driving inflammation in RSV lung disease and that blocking its effect may prove beneficial in bronchiolitis. However, chemokine blockade might be beneficial in primary exposure but paradoxically may enhance disease during reinfection with the same pathogen reflecting different effects at different stages of infection [66]. Mip-1 $\alpha$ is also produced biphasically in both the early (day 1) and late (day 6-7) stages of RSV infection. Mip-1 $\alpha$ depletion reduces the recruitment of T cells after RSV infection, increasing weight loss and illness [53].

In contrast to the CCR5-deficient mice showing higher monocyte influx, mice deficient in CCR2 show less monocyte recruitment and less lung damage upon influenza infection than wild type mice [64]. These findings were confirmed more recently and corroborated by the inverse experiment of overexpression of the CCR2 ligand CCL2 (MCP-1) in the lung, which led to increased monocyte 
influx, damage and mortality after high-dose influenza infection [67]. Further support for protection against influenza through reduced CCL2 action came from the same group using a CCL2 antagonist, which reduced mortality and lung pathology in infected mice. However, studies using less virulent strains or lower doses of influenza virus find contrasting results: CCL2-deficient mice showed higher morbidity and higher virus titers after low-dose infection [68], and neutralization of CCL2 by mAb treatment led to increased lung damage and delayed tissue repair [69]. These conflicting data were somewhat reconciled by a recent study showing complete absence of recruitment of $\mathrm{CD} 11 \mathrm{~b}^{\text {hi }}$ Ly6Chi monocytes after low dose infection of CCR2-deficient mice [70]. Since these monocytes or the cells they differentiate into can present antigen to CD8 T cells, the influenza specific CD8 T cell response is diminished. Pharmacological CCL2 block reduced, but did not abolish monocyte recruitment, thereby improving disease outcome [70]. Hence, massive recruitment of these cells after high-dose infection may lead to severe immunopathology, while in low dose or less virulent infection, less monocytes are recruited leading to optimal CD8 T cell priming. Since it was demonstrated in bacterial infection that the CCL2-CCR2 interaction mainly regulates monocyte egress from the bone marrow which subsequently allows stronger recruitment into infected sites [71], it is conceivable that during virus infection, the same mechanism is at work. In fact, a recent study shows the requirement of CCR2 for bone marrow release of monocytes in infection with MCMV [46]. Interestingly, the production of CCR2 ligands by bone marrowresident leukocytes is dependent on IFN $\alpha \beta$ which is induced during MCMV infection. Since macrophages are essential for local MCMV control in the liver, CCR2 and CCL2 deficient mice die rapidly from infection with this virus [72].

\section{IL-10 and TGF $\beta$ and immune evasion by viruses}

IL-10 is a cytokine with broad anti-inflammatory properties by its suppression of both macrophage and dendritic cell function, including antigen presenting cell function and the production of proinflammatory cytokines [73,74], and more recently by direct effects on T cells [75-77] that keep Th17 cells in check. The presence of closely related homologues of IL-10 in several virus genomes further 
supports its critical role in regulating immune and inflammatory responses [73]. The fact that at least three viral lineages have independently captured host $I L-10$ genes supports the hypothesis that possession of an IL-10 molecule confers an advantage to a DNA virus infecting a mammal, presumably because of its disruptive effect on host immune system signaling [73,78]. Several herpesviruses and poxviruses encode proteins related to the IL-10 family. Human herpesvirus 4 (Epstein-Barr virus) and Orf virus express proteins that are closely related to IL-10 from their human or ovine host, and viral proteins that are more distantly related to IL-10 are encoded by human and primate cytomegalovirus $[73,79]$. Although the absence of IL-10 leads to better clearance of some pathogens with no enhanced immunopathology, during other infections the absence of IL-10 can be accompanied by immunopathology that is detrimental to the host, but does not necessarily affect the pathogen load (reviewed in [74]). IL-10 has important roles in limiting immune responses to viruses but, perhaps not surprisingly, with different outcomes, depending on the virus. Brooks et al [80] showed that compared to acute LCMV infection, chronic infection induced by an LCMV strain differing from the parental strain in only one amino acid is associated with an increase in IL-10 produced by conventional dendritic cells at day 5 post infection. When using the same LCMV strain in IL-10 deficient mice, the virus was cleared rapidly in an acute, self-limiting infection, suggesting that this virus preferentially induced IL-10 to evade the innate and adaptive immune response. Similar results were reported simultaneously by another group who also showed that mAb-mediated IL-10 blockage in chronic LCMV infection resulted in virus control [81]. In persistent MCMV infection, it was shown that IL-10 producing CD4 T cells accumulate in the preferential site of viral replication, the salivary gland, and that IL-10 blocking Abs lead to increased frequencies of IFN $\gamma$-producing CD4 T cells and reduced MCMV titers specifically in this organ [82], similarly to what has been discussed above for LCMV. Increased IL-10 has been linked to other chronic viral infections such as Mouse Mammary Tumour Virus (MMTV) and HCV (reviewed in [83,84]). Recent data from LCMV infection shows that IL-10 production is biphasic, with an initial peak at $2 \mathrm{~d}$ that is similar for acute and chronic infection. Therefore, even in acute 
LCMV infection, blockade or absence of IL-10 increases the CD4 response and enhances protection against the virus [85].

More divergent effects of IL-10 were found in studies of another acute infection, namely influenza. Three groups have investigated infection of mice in the absence of IL-10 signalling and report contrasting results which may be due to differences in viral doses, genetic background of the mice, or the way IL-10 is neutralized [86-88]. Two publications showed that IL-10 promotes morbidity and mortality, in particular when virus doses are used that induce severe disease $[86,87]$. In these studies, both IL-10-deficient mice on the BALB/c background or IL-10 neutralization by mAb injection one day before infection were employed and demonstrated better protection than controls. In one of the studies, IL-10 did not impact sublethal infection, heterosubtypic immunity, or the maintenance of long-lived influenza Ag depots [87] but IL-10-deficient mice displayed dramatically increased survival as compared with wild-type mice when challenged with lethal doses of virus. This increased survival correlated with increased expression of several Th17-associated cytokines, including IL-22, in the lungs of IL-10-deficient mice during the peak of infection, but not with unchecked inflammation or with increased cellular responses, nor effects on viral load and was independent of IFN $\gamma$ production, perforin and IL-17A [87]. The second study showed that IL-10 deficient mice had improved viral clearance and survival after infection as compared to wild-type mice. However, enhanced viral clearance in IL-10 deficient mice was not correlated with increased CD4+ or CD8+ T-cell recruitment into the lung but was correlated with increased pulmonary anti-influenza virus antibody titers, and this was dependent upon the presence of $\mathrm{T}$ cells, primarily CD4 $\mathrm{T}$ cells. In addition, virus-specific antibody produced during the early stages of infection in the respiratory tract of IL-10 deficient but not wild-type mice was sufficient to mediate passive protection against viral challenge of naïve mice [86]. In a third study, an influenza virus dose that induced low mortality in wild type mice was used, and in this case showed that IL-10 receptor blockade, from day 3 post influenza infection onwards, led to aggravated disease, but did not alter the titre of infectious virus in the lungs or virus clearance [88]. In this case, the effect of IL-10 neutralization 
at a later stage post infection may allow the virus to replicate to high titers, which subsequently may lead to an "over-exuberant" immune response once IL10-mediated regulation is removed by IL-10R mAb neutralization. Whether these or other parameters tip the balance between efficient virus clearance and immune-mediated pathology, collectively these results show that the cytokine balance is finely tuned, suggesting that intervention should be considered with caution in acute viral infections, such as influenza. Interestingly, CD8+ T and CD4+ cells are the main source of IL-10 identified in these studies, while little IL10 is produced CD3-negative cells [88]. In a recent follow up [89], it was shown that CD8+ T cells need IL-2 from CD4+ T cells for IL-10 production, and that IL27 from an innate source and Blimp-1 on CD8 cells are also required.

While the above studies concentrate on IL-10 produced by T cells, many innate immune cells can produce this cytokine as well. Monocytes and macrophages are known to be able to secrete IL-10 [74], and recently, neutrophils were added to the growing list of IL-10 producers [90]. In influenza infection, it was shown that NKT cell deficient mice are more susceptible to influenza and that NKT cells are crucial to convert a Gr-1+CD11b+ population from a suppressive to a proinflammatory profile [91]. This population, often termed myeloid-derivedsuppressor cells (MDSCs) comprises cells of both monocyte and neutrophil phenotype, and it will be interesting to determine the exact identity of the cells involved and the regulatory mechanism(s) at work. In a more recent study on the immune response to melanoma, the same group shows immunosuppressive effects mediated by IL-10 that is induced in neutrophils by serum amyloid A. This regulatory neutrophil profile is turned into a pro-inflammatory one by CD1dependent interaction between NKT cells and neutrophils [92], thus suggesting a mechanism also for the observations made in influenza infection.

Another important cytokine with immunoregulaory function is TGF $\beta$. Tinoco et al. [93] compared LCMV strains causing acute or chronic infection and show that TGF $\beta$ induced SMAD2 phosphorylation is enhanced in virus-specific CD8+ T cells early in chronic infection and that TGF $\beta$ contributes to CD8 cell apoptosis. They also demonstrate that in a mouse model with selectively attenuated TGF $\beta$ 
signalling in T cells [94], virus clearance is improved, mainly due to increased specific CD8+ T cell responses. The authors find increased TGF $\beta$ in CD8+ T cells in chronic infection and therefore propose an autocrine loop as a likely mechanism of CD8 cell attenuation. However, the profound regulatory effects of TGF $\beta$ which mediate global effects on immune homeostasis [94] may hinder indepth analysis of the role of TGF $\beta$ in regulating immune responses to acute and chronic viral infections.

\section{IL-17 and other Th17-related cytokines}

The role of IL-17 has been extensively studied in bacterial infection, but less so in viral infection [87]. As described above, IL-10 deficient mice develop a strong protective Th17 response to influenza virus infection, but the same study shows that factors other than IL-17 itself mediate this protective effect. It could be that the production of IL-22 by Th17 cells has a role in protection, as discussed below. IL-17 producing CD8 T cells (Tc17) were shown to arise in influenza infection and to contribute to protection [95]. Treatment with IL-17 neutralizing mAbs reduced protection from challenge with a heterologous influenza strain, suggesting a direct role for this cytokine, however, it is possible that in this scenario, IL-22 levels were also diminished. Similarly, in models of sequential infection by influenza and bacteria, increased susceptibility to bacteria, post influenza infection, was linked to impaired Th17 responses [96].

IL-22 is a cytokine associated with Th17 responses and has been studied predominantly in bacterial infections in the lung [97] and the gut where it promotes epithelial integrity. A tissue-protective role was shown for IL-22 also in liver injury $[98,99]$ and in skin inflammation [100]. Whether or not it also has a role in viral infections is less clear. It was shown that lung NK cells produce IL22 in response to influenza infection, but no significant protective role was found [101]. Intriguingly, treatment with IL-22 neutralizing Ab increased virus titers in this study.

An interesting link between IL-22 and IL-7 was recently described in a model of therapeutic IL-7 treatment for chronic LCMV infection. IL-7 has been shown 
previously to be a promising adjuvant for anti-tumor vaccination [102]. A more recent study demonstrates that IL-7 addition induces naïve and antigen-specific $\mathrm{T}$ cells and increases the production of proinflammatory cytokines, whilst resulting in downregulation of TGF $\beta$. The protective effects of IL-7 are IL-6 dependent and require the downregulation of the cytokine repressor SOCS3 [103]. The resulting enhancement of the immune response leads to accelerated LCMV clearance, and concomitant immune-mediated liver pathology is prevented by increased IL-22 production. IL-22 blockade resulted in high aspartate transaminase (AST) levels indicating increased liver damage [103]. While this study uses exogenous IL-7 for therapeutic purposes, it also raises the question whether IL-7 is produced endogenously in response to infection and whether it contributes to protection. It was shown that systemic TLR treatment induced IL-7 production by hepatocytes [104], and that this effect was dependent on IFN $\alpha \beta$ signalling but not direct TLR signalling in hepatocytes. Collectively, these results suggested that TLR-expressing cells are induced to produce IFN $\alpha \beta$ which then acts on hepatocytes to induce IL-7 [104]. Since viral infections invariably induce IFN $\alpha \beta$ production and pathogens provide TLR agonists, these findings suggest that IL-7 may also be induced by viral infection.

IL-21 is a cytokine associated with Th22 (IL-22 producing T cells which do not produce IL-17) and T Follicular Helper (TFH) cell-responses. A series of papers have shown that CD4-produced IL-21 is crucial to maintain Ag-specific CD8 T cells and protect them from exhaustion, allowing control of chronic LCMV infection [105-107]. In HIV patients, CD4 T cell counts correlate with IL-21 levels $[108,109]$. More recently, a requirement for IL-21 to maintain CD8 T cells was also reported for acute LCMV infection [110], albeit with a less stringent role than in the chronic situation.

\section{Th1 cells and Th1-related cytokines}

Type II IFN or IFN $\gamma$ binds to its distinct heterodimeric receptor formed by the two chains IFN $\gamma R$ 1 and IFN $\gamma$ R2 that signal through Jak1 and Jak2 to 
phosphorylate STAT1 homodimers which then bind to IFN- $\gamma$-activated sequences in the promoters of IFN- $\gamma$-induced genes. IFN- $\gamma$ is produced by many cells of the innate and adaptive immune response including NK cells, CD4+ and CD8+ T cells, and has been suggested to play a role in the immune response to viral infection [12,13]. A nonredundant role for IFN $\gamma$ in controlling Theiler's virus, LCMV and vaccinia virus has been established $[12,13]$. However, in most viral infections, an unequivocal protective role for IFN- $\gamma$, as shown for mycobacterial infections in both mouse and man [111], was not found. This lack of requirement for IFN $\gamma$ for protection against most acute viral infections, could be due to compensation by other IFNs through STAT1 signalling pathways as suggested earlier, or because IFN- $\gamma$ activates anti-viral immunity, by activation of dendritic cells to present antigen and activation of cytotoxic CD8+ T cells [112], via pathways compensated by other cytokines.

It has been demonstrated however, that low-affinity cytotoxic T-lymphocytes require IFN-gamma to clear an acute viral infection [113]. IFN- $\gamma$ production may play a simultaneous role in virus elimination and in inhibiting pathogenic Th2type responses. This is well illustrated by studies of RSV infection (reviewed in [114]). NK cells are transiently present in the early stages of RSV infection of mice and are a major source of IFN $\gamma$ at day 4, when cells of the acquired immune system start to accumulate in the lung. Whereas CD8 T cells can cause enhanced weight loss, IL-12- activated NK cells inhibit lung eosinophilia without causing enhanced illness. However, depletion of both NK and CD8 T cells allows RSV to spread to mediastinal lymph nodes, showing that either subset alone can have antiviral effects, presumably to a large extent by their production of IFN $\gamma$ [115]. Although primary RSV infection is normally dominated by IFN $\gamma$ rather than Th2 cytokines, severe bronchiolitis may be accompanied by evidence of Th2 activation [116]. However, compared to the case for other severe respiratory viral infections leading to lower respiratory tract infections, IFN- $\gamma$ production by peripheral blood mononuclear cells appears to be decreased in RSV disease, perhaps pointing to its role in pathogenesis [114]. STAT1 activation by both type I and type II IFNs has been shown to play an important role in establishing a 
protective, Th1 Ag-specific immune response to RSV infection, however, with an accompanying preferential IL-4, IL-5, and IL-13 induction [117].

\section{Th2- and Th2- related cytokines contribute to pathology in viral responses}

RSV is a major clinical problem causing yearly epidemics of severe lower airway disease in both infants and the elderly. Attempts at vaccination have been frustrated by both the poor immunogenicity of this virus, and the severe immunopathology observed in early vaccine trials. Primary infection generally occurs in infancy, with approximately $5 \%$ of infected infants requiring hospitalization with an apparent link between severe RSV disease and the later development of allergy and asthma [114]. While there is no evidence that natural infection promotes Th2 predominance, development of enhanced eosinophilic disease in children receiving inactivated virus administered with a commonly used adjuvant demonstrated how easily the balance between immune-mediated protection and immune-mediated pathology can be perturbed (reviewed in [114]). During RSV infection some T cells enhance disease, while others control it. In mice, primary signs of disease are reduced by CD4 and/or CD8 T-cell depletion. Depletion of CD4+ T cells or transfer of CD8+ T cells modulates the eosinophilia seen in rVaccinia Virus-RSV-G-protein (RSV-G) primed RSV-infected mice, while eosinophilia can be made to appear in strains that normally do not develop it, if CD8 T cells are depleted or impaired in function. This suggests that Th2 cells promote RSV-induced eosinophilia and that CD8 cells generally inhibit it. As described above, RSV G-induced pathology is caused mainly by the overactive Th2 CD4+ T cells. Thus, the effects of RSV are mediated through the cytokines and chemokines that it induces, and these mediators will necessarily affect the outcome of an infection. The immune background of the neonatal lung is different from that of the adult lung with a general bias towards Th2 responses. For example, CD4+ T cells show hypermethylation in the promoter region of the IFN- $\gamma$ gene, affecting transcription efficiency, and IL-12 gene transcription is reduced in neonatal human monocyte-derived dendritic cells (reviewed in [114]). It may be that these factors in part account for enhanced 
disease severity in RSV-infected infants.

Formaldehyde is widely used in making vaccines but has been associated with atypical enhanced disease during subsequent infection with paramyxoviruses [114]. Openshaw et al. have shown that carbonyl groups on formaldehydetreated vaccine antigens boost Th2 responses and enhance RSV disease in mice, an effect partially reversible by chemical reduction of carbonyl groups. Innate sensing of damaged proteins may thus profoundly affect immunogenicity, changing the balance between protective and deleterious immune responses [118].

\section{IL-9 in anti-viral responses}

IL-9 is a cytokine of great current interest associated with allergic/Th2 responses. High levels of IL-9 are present in bronchial secretions from infants with RSV bronchiolitis. Recently, it has been shown that IL-9 depletion in a vaccine sensitization mouse model enhanced RSV clearance regardless of timing, but caused remarkably different effects on the immunopathogenesis of disease at different phases of the response. Depletion only at the time of RSV challenge had little effect on disease severity, but depletion at both immunization and challenge enhanced disease, increased lymphocytosis and enhances IFN- $\gamma$ and TNF secretion by CD4 T cells while abrogating Th2 cytokine production. Paradoxically, IL-9 depletion at the time of immunization alone alleviated disease by reducing subsequent Th2 cytokine production without a concomitant increase in IFN- $\gamma$ or TNF production [119]. This complex situation illustrates the difficulty of using immune manipulation to modulate acute virus-induced disease, since effects of immune interventions may be critically dependent on the stage of immune priming or recall.

\section{Outlook}

We are coming closer to understanding the complex cytokine interactions in immune responses to infection. This knowledge will enable us to distinguish 
microbe-induced damage from immunopathology and to identify the mechanisms at work, with the prospect of intervention to boost, direct or dampen immune responses as necessary. However, numerous examples cited in this review show how relatively small differences in pathogen load or strain, in host genetic background and in timing and scale of immune intervention change the outcome dramatically, particularly in acute viral responses. Therefore, the increasing complexity of the accumulating data should also teach us a lesson in humility when we attempt to move from our relatively well-controlled models of single infections of clean animals out to the dirty roads of human infectious disease. 


\section{References}

1. Alcami A, Smith GL: Cytokine receptors encoded by poxviruses: a lesson in cytokine biology. Immunol Today 1995, 16:474-478.

2. Bahar MW, Graham SC, Chen RA, Cooray S, Smith GL, Stuart DI, Grimes JM: How vaccinia virus has evolved to subvert the host immune response. J Struct Biol 2011.

3. Isaacs A, Lindenmann J: Virus interference. I. The interferon. Proc $R$ Soc Lond B Biol Sci 1957, 147:258-267.

4. Garcia-Sastre A, Biron CA: Type 1 interferons and the virus-host relationship: a lesson in detente. Science 2006, 312:879-882.

5. Versteeg GA, Garcia-Sastre A: Viral tricks to grid-lock the type I interferon system. Curr Opin Microbiol 2010, 13:508-516.

6. Kotenko SV, Gallagher G, Baurin VV, Lewis-Antes A, Shen M, Shah NK, Langer JA, Sheikh F, Dickensheets H, Donnelly RP: IFN-lambdas mediate antiviral protection through a distinct class II cytokine receptor complex. Nat Immunol 2003, 4:69-77.

7. Sheppard P, Kindsvogel W, Xu W, Henderson K, Schlutsmeyer S, Whitmore TE, Kuestner R, Garrigues U, Birks C, Roraback J, et al.: IL-28, IL-29 and their class II cytokine receptor IL-28R. Nat Immunol 2003, 4:63-68.

8. Witte K, Witte E, Sabat R, Wolk K: IL-28A, IL-28B, and IL-29: promising cytokines with type I interferon-like properties. Cytokine Growth Factor Rev 2010, 21:237-251.

9. Trinchieri G: Type I interferon: friend or foe? J Exp Med 2010, 207:20532063.

10. Liu SY, Sanchez DJ, Cheng G: New developments in the induction and antiviral effectors of type I interferon. Curr Opin Immunol 2011, 23:5764.

11. Feld JJ, Hoofnagle JH: Mechanism of action of interferon and ribavirin in treatment of hepatitis C. Nature 2005, 436:967-972.

12. Muller U, Steinhoff U, Reis LF, Hemmi S, Pavlovic J, Zinkernagel RM, Aguet M: Functional role of type I and type II interferons in antiviral defense. Science 1994, 264:1918-1921.

13. van den Broek MF, Muller U, Huang S, Zinkernagel RM, Aguet M: Immune defence in mice lacking type $I$ and/or type II interferon receptors. Immunol Rev 1995, 148:5-18.

14. Schilte C, Couderc T, Chretien F, Sourisseau M, Gangneux N, GuivelBenhassine F, Kraxner A, Tschopp J, Higgs S, Michault A, et al.: Type I IFN controls chikungunya virus via its action on nonhematopoietic cells. J Exp Med 2010, 207:429-442.

15. Jewell NA, Vaghefi N, Mertz SE, Akter P, Peebles RS, Jr., Bakaletz LO, Durbin RK, Flano E, Durbin JE: Differential type I interferon induction by respiratory syncytial virus and influenza a virus in vivo. J Virol 2007, 81:9790-9800.

16. Durbin JE, Fernandez-Sesma A, Lee CK, Rao TD, Frey AB, Moran TM, Vukmanovic S, Garcia-Sastre A, Levy DE: Type I IFN modulates innate and specific antiviral immunity. J Immunol 2000, 164:4220-4228. 
17. Garcia-Sastre A, Durbin RK, Zheng H, Palese P, Gertner R, Levy DE, Durbin JE: The role of interferon in influenza virus tissue tropism. J Virol 1998, 72:8550-8558.

18. Price GE, Gaszewska-Mastarlarz A, Moskophidis D: The role of alpha/beta and gamma interferons in development of immunity to influenza $A$ virus in mice. J Virol 2000, 74:3996-4003.

19. Szretter KJ, Gangappa S, Belser JA, Zeng H, Chen H, Matsuoka Y, Sambhara S, Swayne DE, Tumpey TM, Katz JM: Early control of H5N1 influenza virus replication by the type I interferon response in mice. J Virol 2009, 83:5825-5834.

20. Koerner I, Kochs G, Kalinke U, Weiss S, Staeheli P: Protective role of beta interferon in host defense against influenza A virus. J Virol 2007, 81:2025-2030.

21. Mordstein M, Kochs G, Dumoutier L, Renauld JC, Paludan SR, Klucher K, Staeheli P: Interferon-lambda contributes to innate immunity of mice against influenza A virus but not against hepatotropic viruses. PLoS Pathog 2008, 4:e1000151.

22. Horisberger MA, Staeheli $P$, Haller O: Interferon induces a unique protein in mouse cells bearing a gene for resistance to influenza virus. Proc Natl Acad Sci U S A 1983, 80:1910-1914.

23. Garcia-Sastre A, Egorov A, Matassov D, Brandt S, Levy DE, Durbin JE, Palese P, Muster T: Influenza A virus lacking the NS1 gene replicates in interferon-deficient systems. Virology 1998, 252:324-330.

24. de Jong MD, Simmons CP, Thanh TT, Hien VM, Smith GJ, Chau TN, Hoang DM, Chau NV, Khanh TH, Dong VC, et al.: Fatal outcome of human influenza A (H5N1) is associated with high viral load and hypercytokinemia. Nat Med 2006, 12:1203-1207.

25. Peiris JS, Cheung CY, Leung CY, Nicholls JM: Innate immune responses to influenza A H5N1: friend or foe? Trends Immunol 2009, 30:574-584.

26. Peiris JS, Hui KP, Yen HL: Host response to influenza virus: protection versus immunopathology. Curr Opin Immunol 2010, 22:475-481.

27. Maines TR, Szretter KJ, Perrone L, Belser JA, Bright RA, Zeng H, Tumpey TM, Katz JM: Pathogenesis of emerging avian influenza viruses in mammals and the host innate immune response. Immunol Rev 2008, 225:68-84.

28. Baskin CR, Bielefeldt-Ohmann H, Tumpey TM, Sabourin PJ, Long JP, GarciaSastre A, Tolnay AE, Albrecht R, Pyles JA, Olson PH, et al.: Early and sustained innate immune response defines pathology and death in nonhuman primates infected by highly pathogenic influenza virus. Proc Natl Acad Sci U S A 2009, 106:3455-3460.

29. Cheung CY, Poon LL, Lau AS, Luk W, Lau YL, Shortridge KF, Gordon S, Guan Y, Peiris JS: Induction of proinflammatory cytokines in human macrophages by influenza A (H5N1) viruses: a mechanism for the unusual severity of human disease? Lancet 2002, 360:1831-1837.

30. Lee SM, Gardy JL, Cheung CY, Cheung TK, Hui KP, Ip NY, Guan Y, Hancock RE, Peiris JS: Systems-level comparison of host-responses elicited by avian H5N1 and seasonal H1N1 influenza viruses in primary human macrophages. PLoS One 2009, 4:e8072. 
31. Zeng H, Goldsmith C, Thawatsupha P, Chittaganpitch M, Waicharoen S, Zaki S, Tumpey TM, Katz JM: Highly pathogenic avian influenza H5N1 viruses elicit an attenuated type $i$ interferon response in polarized human bronchial epithelial cells. J Virol 2007, 81:12439-12449.

32. Kobasa D, Jones SM, Shinya K, Kash JC, Copps J, Ebihara H, Hatta Y, Kim JH, Halfmann $P$, Hatta $M$, et al.: Aberrant innate immune response in lethal infection of macaques with the 1918 influenza virus. Nature 2007, 445:319-323.

33. Boon AC, deBeauchamp J, Hollmann A, Luke J, Kotb M, Rowe S, Finkelstein D, Neale G, Lu L, Williams RW, et al.: Host genetic variation affects resistance to infection with a highly pathogenic H5N1 influenza A virus in mice. J Virol 2009, 83:10417-10426.

34. Guarda G, Braun M, Staehli F, Tardivel A, Mattmann C, Forster I, Farlik M, Decker T, Du Pasquier RA, Romero P, et al.: Type I interferon inhibits interleukin-1 production and inflammasome activation. Immunity 2011, 34:213-223.

35. Belser JA, Zeng H, Katz JM, Tumpey TM: Infection with highly pathogenic $\mathrm{H7}$ influenza viruses results in an attenuated proinflammatory cytokine and chemokine response early after infection. $J$ Infect Dis 2011, 203:40-48.

36. Morens DM, Taubenberger JK, Fauci AS: Predominant role of bacterial pneumonia as a cause of death in pandemic influenza: implications for pandemic influenza preparedness. J Infect Dis 2008, 198:962-970.

37. O'Connell RM, Saha SK, Vaidya SA, Bruhn KW, Miranda GA, Zarnegar B, Perry AK, Nguyen BO, Lane TF, Taniguchi T, et al.: Type I interferon production enhances susceptibility to Listeria monocytogenes infection. J Exp Med 2004, 200:437-445.

38. Carrero JA, Calderon B, Unanue ER: Type I interferon sensitizes lymphocytes to apoptosis and reduces resistance to Listeria infection. J Exp Med 2004, 200:535-540.

39. Auerbuch V, Brockstedt DG, Meyer-Morse N, O'Riordan M, Portnoy DA: Mice lacking the type $I$ interferon receptor are resistant to Listeria monocytogenes. J Exp Med 2004, 200:527-533.

40. Chessler AD, Caradonna KL, Da'dara A, Burleigh BA: Type I Interferons increase host susceptibility to Trypanosoma cruzi infection. Infect Immun 2011.

41. Antonelli LR, Gigliotti Rothfuchs A, Goncalves R, Roffe E, Cheever AW, Bafica A, Salazar AM, Feng CG, Sher A: Intranasal Poly-IC treatment exacerbates tuberculosis in mice through the pulmonary recruitment of a pathogen-permissive monocyte/macrophage population. J Clin Invest 2010, 120:1674-1682.

42. Rayamajhi M, Humann J, Penheiter K, Andreasen K, Lenz LL: Induction of IFN-alphabeta enables Listeria monocytogenes to suppress macrophage activation by IFN-gamma. J Exp Med 2010, 207:327-337.

43. Shinohara ML, Kim JH, Garcia VA, Cantor H: Engagement of the type I interferon receptor on dendritic cells inhibits $T$ helper 17 cell development: role of intracellular osteopontin. Immunity 2008, 29:6878. 
44. Shahangian A, Chow EK, Tian X, Kang JR, Ghaffari A, Liu SY, Belperio JA, Cheng G, Deng JC: Type I IFNs mediate development of postinfluenza bacterial pneumonia in mice. J Clin Invest 2009, 119:1910-1920.

45. Seo SU, Kwon HJ, Ko HJ, Byun YH, Seong BL, Uematsu S, Akira S, Kweon MN: Type I Interferon Signaling Regulates Ly6C Monocytes and Neutrophils during Acute Viral Pneumonia in Mice. PLoS Pathog 2011, 7:e1001304.

46. Crane MJ, Hokeness-Antonelli KL, Salazar-Mather TP: Regulation of inflammatory monocyte/macrophage recruitment from the bone marrow during murine cytomegalovirus infection: role for type I interferons in localized induction of CCR2 ligands. J Immunol 2009, 183:2810-2817.

47. Zuniga EI, Liou LY, Mack L, Mendoza M, Oldstone MB: Persistent virus infection inhibits type $I$ interferon production by plasmacytoid dendritic cells to facilitate opportunistic infections. Cell Host Microbe 2008, 4:374-386.

48. Schlender J, Hornung V, Finke S, Gunthner-Biller M, Marozin S, Brzozka K, Moghim S, Endres S, Hartmann G, Conzelmann KK: Inhibition of toll-like receptor 7- and 9-mediated alpha/beta interferon production in human plasmacytoid dendritic cells by respiratory syncytial virus and measles virus. J Virol 2005, 79:5507-5515.

49. Munir S, Le Nouen C, Luongo C, Buchholz UJ, Collins PL, Bukreyev A: Nonstructural proteins 1 and 2 of respiratory syncytial virus suppress maturation of human dendritic cells. J Virol 2008, 82:87808796.

50. Szretter KJ, Gangappa S, Lu X, Smith C, Shieh WJ, Zaki SR, Sambhara S, Tumpey TM, Katz JM: Role of host cytokine responses in the pathogenesis of avian H5N1 influenza viruses in mice. J Virol 2007, 81:2736-2744.

51. Kozak W, Poli V, Soszynski D, Conn CA, Leon LR, Kluger MJ: Sickness behavior in mice deficient in interleukin-6 during turpentine abscess and influenza pneumonitis. Am J Physiol 1997, 272:R621-630.

52. Hussell T, Pennycook A, Openshaw PJ: Inhibition of tumor necrosis factor reduces the severity of virus-specific lung immunopathology. Eur J Immunol 2001, 31:2566-2573.

53. Tregoning JS, Pribul PK, Pennycook AM, Hussell T, Wang B, Lukacs N, Schwarze J, Culley FJ, Openshaw PJ: The chemokine MIP1alpha/CCL3 determines pathology in primary RSV infection by regulating the balance of $\mathbf{T}$ cell populations in the murine lung. PLoS One 2010, 5:e9381.

54. Kozak W, Zheng H, Conn CA, Soszynski D, van der Ploeg LH, Kluger MJ: Thermal and behavioral effects of lipopolysaccharide and influenza in interleukin-1 beta-deficient mice. Am J Physiol 1995, 269:R969-977.

55. Schmitz N, Kurrer M, Bachmann MF, Kopf M: Interleukin-1 is responsible for acute lung immunopathology but increases survival of respiratory influenza virus infection. J Virol 2005, 79:6441-6448.

56. Pang IK, Iwasaki A: Inflammasomes as mediators of immunity against influenza virus. Trends Immunol 2011, 32:34-41. 
57. Ichinohe $\mathrm{T}$, Pang IK, Iwasaki A: Influenza virus activates inflammasomes via its intracellular M2 ion channel. Nat Immunol 2010, 11:404-410.

58. Allen IC, Scull MA, Moore CB, Holl EK, McElvania-TeKippe E, Taxman DJ, Guthrie EH, Pickles RJ, Ting JP: The NLRP3 inflammasome mediates in vivo innate immunity to influenza $A$ virus through recognition of viral RNA. Immunity 2009, 30:556-565.

59. Thomas PG, Dash P, Aldridge JR, Jr., Ellebedy AH, Reynolds C, Funk AJ, Martin WJ, Lamkanfi M, Webby RJ, Boyd KL, et al.: The intracellular sensor NLRP3 mediates key innate and healing responses to influenza $A$ virus via the regulation of caspase-1. Immunity 2009, 30:566-575.

60. Ichinohe $\mathrm{T}$, Lee $\mathrm{HK}$, Ogura $\mathrm{Y}$, Flavell $\mathrm{R}$, Iwasaki A: Inflammasome recognition of influenza virus is essential for adaptive immune responses. J Exp Med 2009, 206:79-87.

61. Di Paolo NC, Miao EA, Iwakura Y, Murali-Krishna K, Aderem A, Flavell RA, Papayannopoulou $\mathrm{T}$, Shayakhmetov DM: Virus binding to a plasma membrane receptor triggers interleukin-1 alpha-mediated proinflammatory macrophage response in vivo. Immunity 2009, 31:110-121.

62. Alcami A, Lira SA: Modulation of chemokine activity by viruses. Curr Opin Immunol 2010, 22:482-487.

63. Cook DN, Beck MA, Coffman TM, Kirby SL, Sheridan JF, Pragnell IB, Smithies O: Requirement of MIP-1 alpha for an inflammatory response to viral infection. Science 1995, 269:1583-1585.

64. Dawson TC, Beck MA, Kuziel WA, Henderson F, Maeda N: Contrasting effects of CCR5 and CCR2 deficiency in the pulmonary inflammatory response to influenza A virus. Am J Pathol 2000, 156:1951-1959.

65. Tyner JW, Uchida O, Kajiwara N, Kim EY, Patel AC, O'Sullivan MP, Walter MJ, Schwendener RA, Cook DN, Danoff TM, et al.: CCL5-CCR5 interaction provides antiapoptotic signals for macrophage survival during viral infection. Nat Med 2005, 11:1180-1187.

66. Culley FJ, Pennycook AM, Tregoning JS, Dodd JS, Walzl G, Wells TN, Hussell T, Openshaw PJ: Role of CCL5 (RANTES) in viral lung disease. J Virol 2006, 80:8151-8157.

67. Lin KL, Suzuki Y, Nakano H, Ramsburg E, Gunn MD: CCR2+ monocytederived dendritic cells and exudate macrophages produce influenzainduced pulmonary immune pathology and mortality. I Immunol 2008, 180:2562-2572.

68. Dessing MC, van der Sluijs KF, Florquin S, van der Poll T: Monocyte chemoattractant protein 1 contributes to an adequate immune response in influenza pneumonia. Clin Immunol 2007, 125:328-336.

69. Narasaraju T, Ng HH, Phoon MC, Chow VT: MCP-1 antibody treatment enhances damage and impedes repair of the alveolar epithelium in influenza pneumonitis. Am J Respir Cell Mol Biol 2009, 42:732-743.

70. Aldridge JR, Jr., Moseley CE, Boltz DA, Negovetich NJ, Reynolds C, Franks J, Brown SA, Doherty PC, Webster RG, Thomas PG: TNF/iNOS-producing dendritic cells are the necessary evil of lethal influenza virus infection. Proc Natl Acad Sci U S A 2009, 106:5306-5311. 
71. Serbina NV, Pamer EG: Monocyte emigration from bone marrow during bacterial infection requires signals mediated by chemokine receptor CCR2. Nat Immunol 2006, 7:311-317.

72. Hokeness KL, Kuziel WA, Biron CA, Salazar-Mather TP: Monocyte chemoattractant protein-1 and CCR2 interactions are required for IFN-alpha/beta-induced inflammatory responses and antiviral defense in liver. J Immunol 2005, 174:1549-1556.

73. Moore KW, de Waal Malefyt R, Coffman RL, O'Garra A: Interleukin-10 and the interleukin-10 receptor. Annu Rev Immunol 2001, 19:683-765.

74. Saraiva M, O'Garra A: The regulation of IL-10 production by immune cells. Nat Rev Immunol 2010, 10:170-181.

75. Murai M, Turovskaya O, Kim G, Madan R, Karp CL, Cheroutre H, Kronenberg $\mathrm{M}$ : Interleukin 10 acts on regulatory $T$ cells to maintain expression of the transcription factor Foxp3 and suppressive function in mice with colitis. Nat Immunol 2009, 10:1178-1184.

76. Huber S, Gagliani N, Esplugues E, O'Connor W, Jr., Huber FJ, Chaudhry A, Kamanaka M, Kobayashi Y, Booth CJ, Rudensky AY, et al.: Th17 Cells Express Interleukin-10 Receptor and Are Controlled by Foxp3(-) and Foxp3(+) Regulatory CD4(+) T Cells in an Interleukin-10-Dependent Manner. Immunity 2011, 34:554-565.

77. Chaudhry A, Samstein RM, Treuting P, Liang Y, Pils MC, Heinrich JM, Jack RS, Wunderlich FT, Bruning JC, Muller W, et al.: Interleukin-10 signaling in regulatory $T$ cells is required for suppression of th17 cell-mediated inflammation. Immunity 2011, 34:566-578.

78. Hughes AL: Origin and evolution of viral interleukin-10 and other DNA virus genes with vertebrate homologues. J Mol Evol 2002, 54:90-101.

79. Bartlett NW, Dumoutier L, Renauld JC, Kotenko SV, McVey CE, Lee HJ, Smith GL: A new member of the interleukin 10-related cytokine family encoded by a poxvirus. J Gen Virol 2004, 85:1401-1412.

80. Brooks DG, Trifilo MJ, Edelmann KH, Teyton L, McGavern DB, Oldstone MB: Interleukin-10 determines viral clearance or persistence in vivo. $\mathrm{Nat}$ Med 2006, 12:1301-1309.

81. Ejrnaes M, Filippi CM, Martinic MM, Ling EM, Togher LM, Crotty S, von Herrath MG: Resolution of a chronic viral infection after interleukin10 receptor blockade. J Exp Med 2006, 203:2461-2472.

82. Humphreys IR, de Trez C, Kinkade A, Benedict CA, Croft M, Ware CF: Cytomegalovirus exploits IL-10-mediated immune regulation in the salivary glands. $J$ Exp Med 2007, 204:1217-1225.

83. Kane M, Golovkina T: Common threads in persistent viral infections. $J$ Virol 2010, 84:4116-4123.

84. Frebel H, Richter $\mathrm{K}$, Oxenius A: How chronic viral infections impact on antigen-specific T-cell responses. Eur J Immunol 2010, 40:654-663.

85. Brooks DG, Walsh KB, Elsaesser H, Oldstone MB: IL-10 directly suppresses CD4 but not CD8 $\mathrm{T}$ cell effector and memory responses following acute viral infection. Proc Natl Acad Sci U S A 2010, 107:3018-3023.

86. Sun K, Torres L, Metzger DW: A detrimental effect of interleukin-10 on protective pulmonary humoral immunity during primary influenza A virus infection. J Virol 2010, 84:5007-5014. 
87. McKinstry KK, Strutt TM, Buck A, Curtis JD, Dibble JP, Huston G, Tighe M, Hamada $H$, Sell S, Dutton RW, et al.: IL-10 deficiency unleashes an influenza-specific Th17 response and enhances survival against high-dose challenge. J Immunol 2009, 182:7353-7363.

88. Sun J, Madan R, Karp CL, Braciale TJ: Effector $\mathbf{T}$ cells control lung inflammation during acute influenza virus infection by producing IL10. Nat Med 2009, 15:277-284.

89. Sun J, Dodd H, Moser EK, Sharma R, Braciale TJ: CD4(+) T cell help and innate-derived IL-27 induce Blimp-1-dependent IL-10 production by antiviral CTLs. Nat Immunol 2011, 12:327-334.

90. Zhang X, Majlessi L, Deriaud E, Leclerc C, Lo-Man R: Coactivation of Syk kinase and MyD88 adaptor protein pathways by bacteria promotes regulatory properties of neutrophils. Immunity 2009, 31:761-771.

91. De Santo C, Salio M, Masri SH, Lee LY, Dong T, Speak AO, Porubsky S, Booth S, Veerapen N, Besra GS, et al.: Invariant NKT cells reduce the immunosuppressive activity of influenza A virus-induced myeloidderived suppressor cells in mice and humans. J Clin Invest 2008, 118:4036-4048.

92. De Santo C, Arscott R, Booth S, Karydis I, Jones M, Asher R, Salio M, Middleton $\mathrm{M}$, Cerundolo V: Invariant NKT cells modulate the suppressive activity of IL-10-secreting neutrophils differentiated with serum amyloid A. Nat Immunol 2010, 11:1039-1046.

93. Tinoco R, Alcalde V, Yang Y, Sauer K, Zuniga EI: Cell-intrinsic transforming growth factor-beta signaling mediates virus-specific CD8+ $\mathrm{T}$ cell deletion and viral persistence in vivo. Immunity 2009, 31:145-157.

94. Gorelik L, Flavell RA: Abrogation of TGFbeta signaling in T cells leads to spontaneous $T$ cell differentiation and autoimmune disease. Immunity 2000, 12:171-181.

95. Hamada H, Garcia-Hernandez Mde L, Reome JB, Misra SK, Strutt TM, McKinstry KK, Cooper AM, Swain SL, Dutton RW: Tc17, a unique subset of $\mathrm{CD8} \mathbf{T}$ cells that can protect against lethal influenza challenge. $J$ Immunol 2009, 182:3469-3481.

96. Kudva A, Scheller EV, Robinson KM, Crowe CR, Choi SM, Slight SR, Khader SA, Dubin PJ, Enelow RI, Kolls JK, et al.: Influenza A inhibits Th17-mediated host defense against bacterial pneumonia in mice. J Immunol 2011, 186:1666-1674.

97. Aujla SJ, Chan YR, Zheng M, Fei M, Askew DJ, Pociask DA, Reinhart TA, McAllister F, Edeal J, Gaus $\mathrm{K}$, et al.: IL-22 mediates mucosal host defense against Gram-negative bacterial pneumonia. Nat Med 2008, 14:275-281.

98. Radaeva S, Sun R, Pan HN, Hong F, Gao B: Interleukin 22 (IL-22) plays a protective role in $T$ cell-mediated murine hepatitis: IL-22 is a survival factor for hepatocytes via STAT3 activation. Hepatology 2004, 39:1332-1342.

99. Zenewicz LA, Yancopoulos GD, Valenzuela DM, Murphy AJ, Karow M, Flavell RA: Interleukin-22 but not interleukin-17 provides protection to hepatocytes during acute liver inflammation. Immunity 2007, 27:647659. 
100. Wolk K, Kunz S, Witte E, Friedrich M, Asadullah K, Sabat R: IL-22 increases the innate immunity of tissues. Immunity 2004, 21:241-254.

101. Guo H, Topham DJ: Interleukin-22 (IL-22) production by pulmonary Natural Killer cells and the potential role of IL-22 during primary influenza virus infection. J Virol 2010, 84:7750-7759.

102. Pellegrini M, Calzascia T, Elford AR, Shahinian A, Lin AE, Dissanayake D, Dhanji S, Nguyen LT, Gronski MA, Morre M, et al:: Adjuvant IL-7 antagonizes multiple cellular and molecular inhibitory networks to enhance immunotherapies. Nat Med 2009, 15:528-536.

103. Pellegrini M, Calzascia T, Toe JG, Preston SP, Lin AE, Elford AR, Shahinian A, Lang PA, Lang KS, Morre M, et al.: IL-7 engages multiple mechanisms to overcome chronic viral infection and limit organ pathology. Cell 2011, 144:601-613.

104. Sawa Y, Arima Y, Ogura H, Kitabayashi C, Jiang JJ, Fukushima T, Kamimura D, Hirano T, Murakami M: Hepatic interleukin-7 expression regulates $\mathrm{T}$ cell responses. Immunity 2009, 30:447-457.

105. Yi JS, Du M, Zajac AJ: A vital role for interleukin-21 in the control of a chronic viral infection. Science 2009, 324:1572-1576.

106. Elsaesser H, Sauer K, Brooks DG: IL-21 is required to control chronic viral infection. Science 2009, 324:1569-1572.

107. Frohlich A, Kisielow J, Schmitz I, Freigang S, Shamshiev AT, Weber J, Marsland BJ, Oxenius A, Kopf M: IL-21R on T cells is critical for sustained functionality and control of chronic viral infection. Science 2009, 324:1576-1580.

108. Iannello A, Boulassel MR, Samarani S, Debbeche O, Tremblay C, Toma E, Routy JP, Ahmad A: Dynamics and consequences of IL-21 production in HIV-infected individuals: a longitudinal and cross-sectional study. J Immunol 2010, 184:114-126.

109. Iannello A, Tremblay C, Routy JP, Boulassel MR, Toma E, Ahmad A: Decreased levels of circulating IL-21 in HIV-infected AIDS patients: correlation with CD4+ T-cell counts. Viral Immunol 2008, 21:385-388.

110. Yi JS, Ingram JT, Zajac AJ: IL-21 deficiency influences CD8 T cell quality and recall responses following an acute viral infection. $J$ Immunol 2010, 185:4835-4845.

111. Cooper AM: Cell-mediated immune responses in tuberculosis. Annu Rev Immunol 2009, 27:393-422.

112. Kagi D, Ledermann B, Burki K, Zinkernagel RM, Hengartner H: Molecular mechanisms of lymphocyte-mediated cytotoxicity and their role in immunological protection and pathogenesis in vivo. Annu Rev Immunol 1996, 14:207-232.

113. Von Herrath MG, Coon B, Oldstone MB: Low-affinity cytotoxic Tlymphocytes require IFN-gamma to clear an acute viral infection. Virology 1997, 229:349-359.

114. Openshaw PJ, Tregoning JS: Immune responses and disease enhancement during respiratory syncytial virus infection. Clin Microbiol Rev 2005, 18:541-555.

115. Hussell T, Openshaw PJ: IL-12-activated NK cells reduce lung eosinophilia to the attachment protein of respiratory syncytial virus 
but do not enhance the severity of illness in CD8 $T$ cellimmunodeficient conditions. J Immunol 2000, 165:7109-7115.

116. Lee FE, Walsh EE, Falsey AR, Lumb ME, Okam NV, Liu N, Divekar AA, Hall $\mathrm{CB}$, Mosmann TR: Human infant respiratory syncytial virus (RSV)specific type 1 and 2 cytokine responses ex vivo during primary RSV infection. J Infect Dis 2007, 195:1779-1788.

117. Durbin JE, Johnson TR, Durbin RK, Mertz SE, Morotti RA, Peebles RS, Graham BS: The role of IFN in respiratory syncytial virus pathogenesis. J Immunol 2002, 168:2944-2952.

118. Moghaddam A, Olszewska W, Wang B, Tregoning JS, Helson R, Sattentau QJ, Openshaw PJ: A potential molecular mechanism for hypersensitivity caused by formalin-inactivated vaccines. Nat Med 2006, 12:905-907.

119. Dodd JS, Lum E, Goulding J, Muir R, Van Snick J, Openshaw PJ: IL-9 regulates pathology during primary and memory responses to respiratory syncytial virus infection. J Immunol 2009, 183:7006-7013. 